\title{
沉积岩新种一一偏岭石粘土岩的研究
}

\author{
刘 长 龄
}

（冶金部天津地质调查所）

粘土新矿物偏岭石发表后 ${ }^{[1]}$, 作者等又于 1964 年去偏岭等地区进行工作, 通过研究, 有些 新的认识, 现仅从岩石学方面的研究简要报道如下:

一、偏岭石粘土岩的地质产状偏岭石粘土岩一般呈单矿粘土岩产出, 与上下围岩呈 平行整合接触, 均属上石炭统陆相沉积岩层. 上部地层是二迭系陆相碎屑岩、粘土岩与侏罗系 煤系地层, 整个偏岭石粘土岩的层厚一般从 1 米左右至 3 - 5 米以上. 地表露头不好, 在长数 十公里的范围内, 断续出露, 有时尖灭, 呈层状或似层状及透镜状产出. 其顶底板围岩一般为 含有机质的高岭石泥岩(野外称“黑色页岩”)或硬质粘土, 以及含砂、粉砂质粘土岩或粘土质粉 砂岩与细砂岩, 各地段剖面岩性稍有不同. 一般不与煤层直接伴生, 或局部可见薄煤层或煤 线, 但无燃烧痕迹及温度梯度产生不同的烘烤带. 区内无火成岩分布, 也无热液蚀变的迹象.

二、偏岭石粘土岩的岩石类型 根据外观特征及结构构造等不同 ${ }^{[2]}$, 可进一步将其划 分为下列几种主要岩石类型(亚种):

1. 洁白色致密块状的“偏岭石泥岩”（包括它在风化及退后生作用中变成的粉末状水化偏 岭石粘土): 结晶较细者表面平滑, 具近似玻璃或油脂光泽, 节理裂纹不发育, 半贝壳状断口; 结晶较粗者表面粗粘具瓷状或土状外貌 (似人工熟料), 节理裂纹较发育, 常有少量次生氧化铁 (赤铁矿、水赤铁矿及针铁矿等) 填充, 具不平坦或参差状断口. 在薄片中观察, 一般呈隐晶质 蠕状或稀蠕状重结晶结构 (图 1), 蠕状晶体表面模糊(单偏光下呈云䟓状), 清澈透明者少. 因 此, 这种重结晶主要为成岩作用所致. 此外, 岩石中常含有少量的石英(一般为自生, 可见具长 柱状双锥体外形 ${ }^{[1]}$ ) 及锆石等 (自生锆石, 延长率 $<2.3$, 属沉积成因).

2. 灰一蓝灰色致密块状的“偏岭石粘土岩”(包括它在风化及退后生作用中变成的粉末状水 化偏岭石粘土): 一般结晶较差, 含非晶质或残存的水铝英石略多些. 表面平滑至稍粗粘状, 近于玻璃光泽一土状光泽, 节理裂纹不发育或稍发育, 半贝壳状一一不平坦断口. 它的颜色 因重结晶可转变为灰白、浅灰白直至洁白色偏岭石泥岩 (可因色泽不同显条纹状, 这种重结晶 的差异, 绝非“煤层自燃的残留结构”). 其中蝡状重结晶结构不大发育, 蠕状偏岭石往往少而 小(且多模糊状), 多呈隐晶质及胶状, 有时由于偏岭石的重结晶可见十字消光, 蠕状卷曲. 在 成岩作用阶段水铝英石凝胶脱水使体积收缩时,产生的偏岭石具负双折射;而胶体偏岭石因受 张力作用所产生的正双折射则是偶见的. 还偶见偏岭石具鰂状结构（鲗粒直径 $0.3-0.4$ 毫 米), 其外圈也呈十字消光(理由同上). 也常含少量的石英及锆石等自生矿物.

3. 浅灰白一洁白色粗粘块状或略具条纹状的 “偏岭石粗泥岩”: 一般呈粗鱗片及蠕状重结 晶结构, 结晶粗大, 最大者可达 2 毫米以上, 也有少量或局部较多的隐晶质偏岭石集合体呈定

本文 1978 年 3 月 10 日收到. 1979 年 3 月 3 日收到修改稿. 


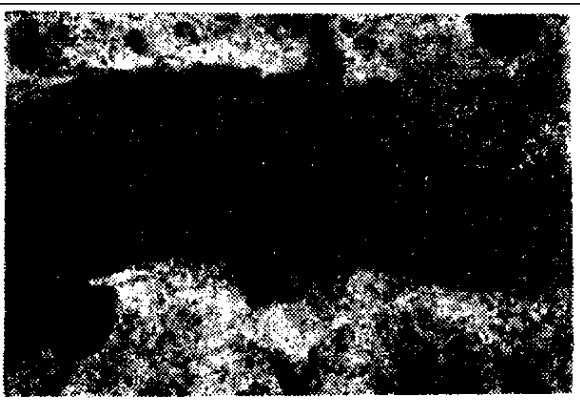

图 1 蠕状偏岭石表面模糊,单偏光. $\times 100$

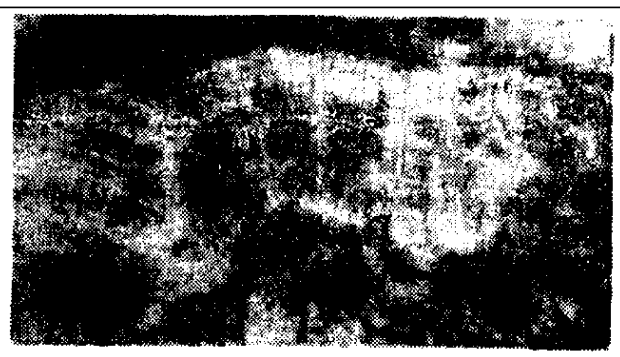

图 2 蠕状偏岭石 001 幦纹完全,正交偏光. X100

向排列. 前者清澈透明(图 2), 可能主要是后生作用重结晶的结果(有时还可见少量较小的模 糊状蠕状晶体残留); 而后者尚被少量有机质浸染或包裹. 其它杂质含量甚少. 可见在成岩作 用中重结晶的粗蠕状偏岭石又在后生作用中为后生的偏岭石交代, 还可见自生石英在后生作 用中受偏岭石溶蚀. 稀少的自生锆石可呈集合体结晶 (延长率均 $<2.3$ ).

4. 洁白色砂岩状的 “含叶蜡石无定形铝氧偏岭石泥岩”：呈粗鳞片斑状重结晶结构，基质 为隐晶质集合体，偏岭石斑晶一般为粗鳞片，还能见到成岩阶段的模糊残留部分，而未见到蠕 状晶体. 由于在后生阶段进一步重结晶，那种在成岩阶段重结晶模糊状晶体已基本变为清澈 透明. 少量叶蜡石及无定形铝氧可能呈微细镶㰠晶体于偏岭石中, 也有无定形铝氧沿裂隙分 布 (后生及风化作用所成,因生成 2:1 层的叶蜡石后,有游离 $\mathrm{Al}_{2} \mathrm{O}_{3}$ 析出). 叶蜡石经 X射线衍 射仪分析见 $9.2627 \AA$ 、3.0639 等峰显著. 此外,还有很少的自生锆石,偶见自生石英.

5. 炭质页岩状的 “偏岭石粗泥岩”：黑灰或深灰色，沿裂隙因氧化及次生多水高岭石化而 呈浅灰色,粗精似细砂岩－参差状断口，暗谈光泽。岩石绝大部分呈粗大的蝡状结晶结构,并有 表面吸附或浸染状的有机质残留,晶体中心因有机质氧化而螁色. 微具多色性, $\mathrm{Ng}=$ 浅黄楬 色, $\mathrm{Nm}=$ 浅黄蝎色, $\mathrm{Np}=$ 无色. 此外, 除少量多水高岭石 $(\mathrm{X}$ 射线衍射仪分析 $10.345 \AA$ 峰 显著)外，还有很少的自生石英及锆石等. 可见在退后生及风化作用中，偏岭石被多水高岭石 交代或割切(前者受有机质浸染，后者则没有，说明后者是前者在后生及风化作用中由于有机 质羓化及酸性地下水溶解后再晶出的），还可见自生石英被后生作用中的偏岭石交代割切,而 偏岭石后又被多水高岭石交代. 也有早期的细蠕状偏岭石被包裹在自生石英内. 还有偏岭石 重结晶时, 可包裹自生石英及自生锆石. 偏岭石可因有机质氧化而螁色并成为花辦状集合体.

6. 淡黄灰白色 “含粉砂硅质的偏岭石泥页岩”: 岩石具薄层理或显微层理, 主要由细鳞片 状偏岭石集合体组成,而蠕状偏岭石较少，还有少量呈砂及粉砂状的微斜长石及自生石英(碎 屑成因的很少)，可见微斜长石与石英受偏岭石交代呈残留的不规则形状. 偶见电气石碎屑受 偏岭石溶蚀而成蚀弯. 另有很少的水白云母,水黑云母,氧化铁及金红石等杂质矿物. 在较大 的偏岭石底切面中测得 $(-) 2 \mathrm{~V}=25^{\circ}-50^{\circ}$. 可见偏岭石在退后生作用中, 有后期细粒偏岭 石交代成岩及进后生作用 (早期) 的蠕状偏岭石,并受挤压而错开. 可见少量自生石英与土壤 中胶硅体的外形十分相似，因而推想其成因也是与之类似或相关的. 当微斜长石等砂及粉砂 质与硅质(自生石英)等杂质含量减少时, 就逐渐向偏岭石页岩过渡.

上述六种偏岭石的岩石类型,以洁白色的偏岭石泥岩分布较多而普遍,其它类型仅在不同 的部位富集或局部存在.

三、偏岭石粘土岩的化学成分（表 1) 证明多呈单矿粘土岩产出, $\mathrm{SiO}_{2}: \mathrm{Al}_{2} \mathrm{O}_{3}$ 比值一般 在 2:1 左右. 根据光谱半定量分析, 偏岭石粘土岩内还含有少量 $\mathrm{Y}_{2} \mathrm{O}_{3} 、 \mathrm{La}_{2} \mathrm{O}_{3} 、 \mathrm{CeO}_{2}$ 及 $\mathrm{B} 、 \mathrm{Ba} 、 \mathrm{Sr} 、$ 


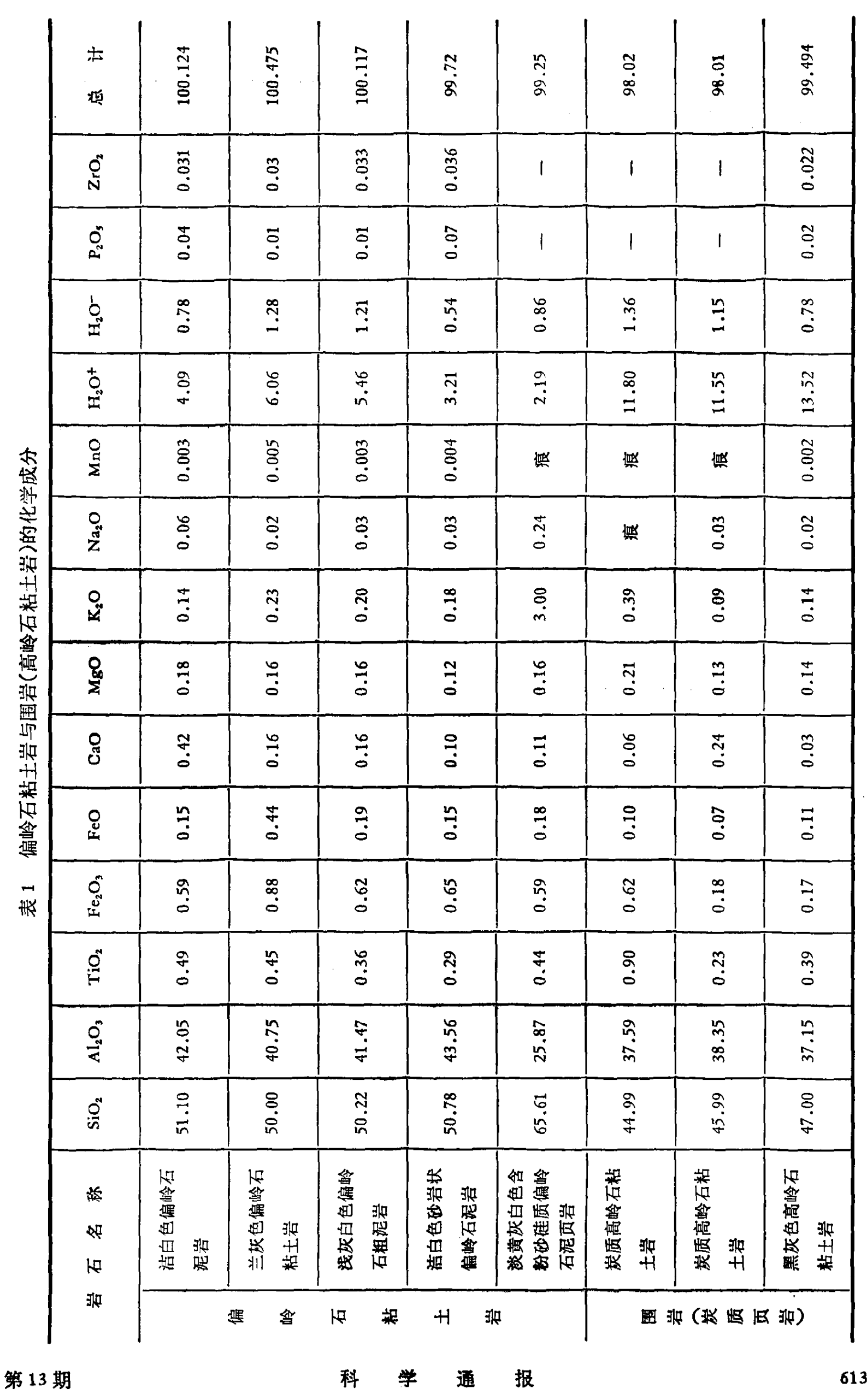


$\mathrm{Pb} 、 \mathrm{Sn} 、 \mathrm{Ga} 、 \mathrm{Cr} 、 \mathrm{Ni} 、 \mathrm{Cu} 、 \mathrm{~V} 、 \mathrm{Ag}$ 等.在后生作用发育的洁白色砂岩状偏岭石泥岩内, $\mathrm{Pb}$ 及 $\mathrm{Y}_{2} \mathrm{O}_{3}$ 、 $\mathrm{La}_{2} \mathrm{O}_{3} 、 \mathrm{CeO}_{2}$ 等成倍增加, 这与当时地下水的性质有关 (后生阶段).

四、偏岭石粘土岩的成因 根据偏岭石粘土岩的地质产状、物质成分及结构构造特征 等情况,笔者认为它属于温湿气候的湖沼相胶体化学沉积,在成岩后生作用中经水铅英石转变 而成的. 至今偏岭石泥岩及围岩 (高岭石泥岩等) 还含有少量有机质, 证明当初有机质起了一 定的作用 (当时水体浅,含一定数量的氧,特别是细菌的作用使有机质分解为腐植酸). 在腐植 酸 (还有 $\mathrm{CO}_{2}$ 及硫氢化合物等具有高度的化学活性和分解多种岩石的能力) 的影响下,硅酸盐 矿物分解为氧化铝和氧化硅的凝胶状混合物, 因而形成水铝英石. 水铝英石为标准的表生矿 物, 它有许多不同的地质产状, 但其生成多与硫化物的氧化及腐植酸造成的酸性介质环境有 关, 即利于分解铝硅酸盐矿物. 当 $\mathrm{pH}=4.8-5.0$ 时, 可沉淀为 $\mathrm{Al}_{2} \mathrm{O}_{3}: \mathrm{SiO}_{2}=1: 2$ 的沉淀物 ${ }^{[3 \mathrm{j}}$. 此地当初形成的水铝英石并不独特, 所不同的是迅速被覆盖层 (“炭质页岩” 等) 覆盖, 在成岩 作用中,由于上复岩层的压力而脱胶体水 (所剩不多), 并产生脱水裂缝及凝胶的凝结(体积缩 小). 在应力作用下 (由于分子排列与分子间距离的改变及电子层的变形)产生双折射, 可见十 字消光及波状消光, 进而形成偏岭石的蠕状及鳞片状等结晶. 有时重结晶晶体的 $\{001\}$ 辟纹 逐渐减少,这可能因“半晶质矿物”的晶体结构沿 C 轴失序(或失去周期性)有关 ${ }^{[4]}$.

根据所含有机质的氧化温度 $400^{\circ} \mathrm{C}$ 左右(低于高岭石脱结构水温度)及所含部分包裹体爆 波温度低于高岭石脱结构水温度,更可证明偏岭石非 “煤层自煤” 的结果. 还做了岩石的高温 差热分析、 $X$ 射线衍射仪分析、电子探针及红外光谱分析等.

偏岭石粘土岩的发现, 不仅增加了一个沉积岩的新种. 并且在我国所发现的几十种新矿 物中, 所构成的单矿岩新岩石, 这还是第一次, 因而对我国岩石学界有着重要的意义. 同时它 又是一种质量较纯的硬质耐火粘土与陶瓷原料, 具有一定的经济价值.

\title{
参文献
}

[1] 刘长龄、刘德业等,科学通报, 1963, 10: 59-63.

[2]刘长龄, 中国地质学会论文选集岩石部分, 1964, 333-346.

[3] Ф. B. 丘赫洛夫,胶体矿物学原理,科学出版社, 1965.

[4] Brindley, G. W. \& Nakahira, M., J. Amer. Ceram. Soc., 42 (1959)7: 311-324.

\section{A NEW SEDIMENTARY ROCK-PIANLINTIC CLAY ROCK}

\author{
LiU Chang-Ling (刘长龄)
}

\begin{abstract}
The pianlintic clay rock consists of the new mineral pianlinite. The rock occurs in the mineral's pure form, so it can be used as refractory and porcelain material. The rock formation generally about $1 \mathrm{~m}$ thick may run from $3 \mathrm{~m}$ to $5 \mathrm{~m}$ thick, and is stratified, layered or lenticular. It is in plano-conformity with its top and bottom wall rocks and is with them of sedimentary rock formation of terrestrial facies. They all belong to the upper Carboniferous System's C.
\end{abstract}

